the Cavendish Laboratory, Cambridge, in 1911. 'This instrument was the only one used by Wilson for his many subsequent researches and is preserved now in the Cavendish Museum where it is still, after forty years, as capable of producing perfect ray-tracks as when it was first demonstrated. In 1913, the Cambridge Instrument Co. obtained permission to make a cloud chamber similar to Wilson's original model ; and the Company's first instrument, together with subsequent developments, such as the WilsonShimidzu raytrack apparatus (1921), the student's demonstration cloud chamber (1927) and the reciprocating cloud chamber built for the 1951 Festival of Britain, are all fully described and illustrated in the monograph.

\section{Standards of Light at the National Physical Lab-} oratory

"LIGHT" is the second in the series of pamphlets on units and standards of measurement employed at the National Physical Laboratory, Teddington (pp. 8. London: H.M.S.O., 1952; 6d.). The first dealt with the fundamental units of length, mass and time, and the third will deal with electrical units. In the pamphlet on light, the units and systems of measurement used in the Photometry, Colorimetry and Radiometry Sections of the Light Division of the Laboratory are defined. The units are those normally employed in reports and certificates issued by the Laboratory. Brief particulars deseribing the derivation of the units are provided, and reference is made to those which are accepted internationally. The topics discussed in the photometry section of the pamphlet are the candela, the unit of luminous intensity; the lumen, the unit of luminous flux; the distinction between the units of illumination on the British and metric systems; the stilb and the nit ; the scotopic system of photometry ; and colour temperature. The requirements of the standard trichromatic system of colorimetry adopted by the Commission Internationale de l'Fclairage are set out clearly in the colorimetry section; and, under the third heading of the pamphlet, "Radiometry", the instruments, particularly the Callendar radiation balance and its more recent successor the Guild drift radiometer, for the measurement of the rate of transference of energy by electromagnetic radiation, are briefly discussed. Industrial and research laboratories will find this series of pamphlets most helpful in interpreting test certificates and in ensuring that results of measurements are expressed in agreed and internationally recognized units.

\section{Principles of Extraction and Refining of Metals}

THE Institution of Metallurgists has published the five lectures on the "Principles of the Extraction and Refining of Metals" given under the presidency of Mr. E. W. Colbeck at its refresher course in 1950. Starting off with an introductory lecture on the use of physical chemistry in extraction operations, which is concerned mainly with thermodynamic principles, the place of mineral dressing in extraction metallurgy is then considered; this is, in the main, economic and technical. A lecture of unusual interest on the principles of ore reduction, by Prof. C. W. Dannatt, goes far towards systematizing the large number of procedures which are used for obtaining crude metal from its ore. 'T'he fundamentals of the production of ingots are then discussed, and the course is concluded by a lecture on the principles underlying refining processes, using the fundamental chemical principles previously outlined. All who are concerned with the extraction and refining of metals will find in this short monograph a large amount of material of direct interest, much of it by no means easy to find, nor so well digested, elsewhere. As is said in the concluding paragraph of the last lecture: "The refiner will find it vastly to his advantage to employ thermodynamics in order to recognize both the results which may theoretically be achieved in the ideal process, and those which are inherently impossible under his conditions of working".

\section{King George III Collection of Scientific Instru- ments}

A DESCRIPTIVE catalogue of the King George III collection of scientific instruments, issued by the Science Museum, London (pp. $92+8$ plates; London: H.M.S.O., $1951 ; 7 s .6 d$. net), is of interest in throwing light on the activities of individual instrument-makers practising during the latter half of the eighteenth century. The catalogue is divided into sections according to the various branches of science recognized at the present time, for it should be realized that in the days of George III scientific specialization was not known, since the philosophers-as they were called-did not confine their studies to one branch of knowledge. The sections of the catalogue include mechanics, heat, pneumatics and hydrostatics, chemistry, astronomy and time measurement, optics, surveying and mathematical instruments, acoustics, magnetism, electricity, manuscripts and miscellaneous. The catalogue is illustrated and concludes with notes on the location of the other portions of the original collection and a list of makers of the instruments.

\section{Colonial Plant and Animal Products}

IN the latest issue of the quarterly journal of the Colonial Products Advisory Bureau (Plant and Animal) (2, No. 3), R. H. Kirby continues his series of articles on seaweeds in commerce. Besides accounts of the use of agar-agar in the British Commonwealth and other countries, Kirby also describes the manufacture of algin in the United States and other parts of the world. Other articles include one on aromatic grasses of commercial importance by E. Brown and W. S. A. Matthews, and the market for mangoes and mango products by E. H. G. Smith. Reports of recent investigations at the Colonial Products Advisory Bureau include that on the use of trigona wax from Tanganyika, manila hemp from Malaya, pewar or peach nuts from Trinidad, a description of drying trials with goat skins in the Sudan and the possibilities of using cocoa husks from the Gold Coast as a source of furfural.

\section{Annals and Magazine of Natural History}

For a century and a quarter the Annals and Magazine of Natural History has held an honoured place among biological journals; all-embracing in its earlier years, it has of late tended to include particularly systematic and morphological papers in zoology, palæobotany and palæontology. The proprietors of the journal, Messrs. Taylor and Francis, Ltd., with the support of the editorial board, have now decided to widen its scope by combining with it the Journal of Botany, which had to cease publication during the Second World War. The editorial board, Sir Guy Marshall, Dr. W. T. Calman, Prof. H. L. Hawkins and Mr. W. N. Edwards, will thus have the assistance of Dr. George Taylor, keeper of botany 